\title{
ESTRATIGRAFIA DE SEQUÊNCUAS DAS FORMAÇÕES CAMPO MOURÃO (PARTE SUPERIOR) E TACIBA, GRUPO ITARARÉ, LESTE DA BACIA DO PARANÁ
}

\begin{abstract}
SEQUENCE STRATIGRAPHY OF THE CAMPO MOURÃO (UPPER PART) AND TACIBA FORMATIONS, ITARARÉ GROUP, EASTERN PARANÁ BASIN The chronostratigraphic framework of the Campo Mourão (upper part) and Taciba formations, Itararé Group was investigated through a subsurface study in the eastern flank of the Paraná Basin. A total of five depositional sequences were recognized, each represented by an upward increase in the argillaceous content (sandstone to diamictite to shale). The upper part of basal sequence 1 is formed by a thick diamictite overlain by the Lontras Shale; these glaciomarine and marine systems may constitute the transgressive tract of the sequence and represent the top of Campo Mourão Formation/cycle. The Lontras Shale (or Member) is not restricted to the Santa Catarina State; instead it is recognized throughout the eastern flank of the basin.

The sequence 2 is represented in the basal portion by the sandstones of Rio Segredo Member (base of Taciba Formation/cycle). The next sequences are similar to the previous one, including some particular patterns: as the basal sandstones form clastic wedges, the sequence may be represented exclusively by diamictites. The clastic wedges of sequences 2 and 4 were supplied from east and northeast; the western margin also contributed as source of coarse elastics.

Sequences 4 and 5 were studied in detail, since they were reached by several shallow wells near the outcrop belt. The sequence 4 clearly displays facies change from marine in the south (Passinho Shale) to delta front in center-south, and to coal-bearing delta plain in the north. The occurrence of sequence 5 is restricted to southern Paraná and northern Santa Catarina; it presents deltaic sandstone deposits intercalated with marine shales/sandstones and glaciomarine diamictites. Despite some transitional characteristics shown by the upper part of Itararé Group (sequences 4 and 5), it is noteworthy the unconformable relationship of the Group with the overlying, post-glacial Triunfo Member of Rio Bonito Formation.

Keywords: Sequence Stratigraphy, Harare Group, Eastern Paraná Basin, Paleogeography

RESUMO O arcabouço cronoestratigráfico da parte superior da Formação Campo Mourão e a Formação Taciba, Grupo Itararé, foi investigado através do estudo de sondagens executadas no flanco leste da Bacia do Paraná. Foram identificadas cinco seqüências deposicionais, cada uma constituída por uma sucessão ascendente de aumento de argilosidade (arenito, diamictito e folhelho); este arranjo mímica o dos ciclos/formações que representam o Grupo Itararé

A parte superior da seqüência basal (1) é constituída de espesso diamictito sobreposto pelo Folhelho Lontras, sendo que esses sistemas glácio-marinho e marinho constituem o trato transgressivo da seqüência e representam o topo do ciclo/Formação Campo Mourão; o Folhelho/Membro Lontras pode ser reconhecido em toda a margem leste da bacia. A seqüência 2 contém em sua porção basal os arenitos correspondentes ao Membro Rio Segredo da Formação Taciba.

As demais sequiências têm padrão semelhante ao das anteriores, e os arenitos basais de cada sequiência, por formarem cunhas elásticas localizadas, podem estar ausentes e as seqüências serem representadas simplesmente por uma espessa "caixa" de diamictitos. A cunha arenosa da seqüência 3 origina-se de leste e de nordeste, e nela nota-se uma rápida variação faciológica de deposição fluvial para deltaica-estuarina (no mesmo sentido de leste para oeste). Outras contribuições de elásticos grossos provêm da margem oeste da bacia.

As seqüências 4 e 5 foram objeto de detalhamento faciológico, pois também foram amostradas por perfuracões rasas. Nota-se na seqüência 4 uma importante variação faciológica, no sentido de sul para norte, desde sistemas marinho ("Folhelho Passinho") à frente deltaica e à planície deltaica; a seqüência 5, restrita ao sul do Paraná e norte catarinense, contém intercalações de sistemas deltaicos, marinhos e glácio-marinhos. É marcante a relação discordante do Grupo Itararé (seqüências 4 e 5) com o Membro Triunfo (Formação Rio Bonito) sobreposto.

Palavras-chave: Estratigrafia de Seqüências, Grupo Itararé, Leste da Bacia do Paraná, Paleogeografia
\end{abstract}

INTRODUÇÃO O Grupo Itararé, de idade westphaliana a artinskiana, representa uma complexa unidade da Bacia do Paraná, tanto do ponto de vista deposicional-paleogeográfíco quanto do arranjo cronoestratigráfíco. Isto se deve principalmente às condições glaciais que dominaram a sua deposição, proporcionando uma grande variedade de fácies e sistemas deposicionais de complexa distribuição vertical, lateral e temporal.

Uma importante divisão litoestratigráfica do Grupo Itararé foi proporcionada por Schneider et al (1974), ao identificar e mapear as formações Campo do Tenente, Mafra e Rio do Sul no estado de Santa Catarina e sul do Paraná. Deve-se a França \& Potter (1988), entretanto, a proposta de um arcabouço estratigráfico do Grupo Itararé em toda a Bacia do Paraná: este trabalho identificou três grandes ciclos, de argilosidade crescente para cima, que foram denominados de formações Lagoa Azul, Campo Mourão e Taciba. Os constituintes litológicos de cada ciclo receberam designações formais, como o Membro Lontras do topo do segundo ciclo/Formação Campo Mourão, ou os arenitos, diamictitos e folhelhos do terceiro ciclo/Formação Taciba, denominados respectivamente de membros Rio Segredo, Chapéu do Sol e Rio do Sul. Na recente proposta da Petróleo Brasileiro S.A. Petrobrás foi eliminado o Membro Lontras, e o Membro Rio Segredo foi deslocado para o topo da Formação Campo Mourão (Milani et al. 1994).

O primeiro objetivo deste trabalho foi mapear o intervalo entre a parte superior da Formação Campo Mourão e a Formação Taciba, dentro de um arcabouço cronoestratigráfíco de Estratigrafia de Seqüências, enfocando o segmento leste paranaense da Bacia do Paraná. Adicionalmente foi investigado detalhadamente o topo da Formação Taciba na margem leste da bacia, para compreender a evolução paleogeográfica da unidade pós-glacial, o Membro Triunfo da Formação Rio Bonito.

CONTEXTO GEOLÓGiCO No segmento leste paranaense da Bacia do Paraná (Fig. 1) destaca-se o Arco de Ponta Grossa, um alinhamento orientado noroeste-sudeste. Ao longo do eixo do arco, o adensamento de curvas estruturais do topo do Grupo Itararé indica um mergulho que alcança $2^{\circ}$. Na área em apreço o Grupo Itararé atinge uma espessura de $910 \mathrm{~m}$ (poço 2-RI-1-PR, figura 1), e tem limites discordantes com as formações Ponta Grossa (Devoniano) e Rio Bonito (Kunguriano); este último contato, entretanto, é considerado concordante no sul do Paraná e em Santa Catarina.

Poços da faixa central paranaense, como o 2-RI-1-PR (RI-1, Fig. 1), exibem claramente os três grandes ciclos de argilosidade crescente para cima propostos por França \& Potter (1988); cada ciclo é formado pela sucessão de arenitos, diamictitos e pelitos (estes incluindo folhelhos, siltitos e ritmitos delgados). O topo argiloso do ciclo intermediário/Formação Campo Mourão corresponde ao Folhelho/Membro Lontras, que, no entanto, só foi identificado pelos autores supracitados no Estado de Santa Catarina, seguindo a proposta original de Schneider et al. (1974). O ciclo superior/Formação Taciba é composto pelos membros Rio Segredo (arenoso basal e amplamente distribuído), Chapéu do Sol (diamíctico, característico da porção superior da formação no oeste catarinense, na maior parte do Paraná e também em S. Paulo) e Rio do Sul (síltico-argiloso da porção superior, bem representado no sudeste do Paraná e leste de Santa Catarina).

O presente trabalho, ao reconhecer e mapear o Folhelho Lontras em todo o Estado do Paraná e mesmo em S. Paulo, confere-lhe maior importância lito-cronoestratigráfíca por representar um evento transgressivo regional. Deve-se mencionar que esse marco de correlação foi reconhecido anteriormente em projeto inédito da Petrobrás, de 1983.

As formações Campo Mourão e Taciba apresentam o padrão característico de afinamento para o topo somente na faixa central paranaense. Em direção à margem leste da bacia ocorrem intercalações arenosas que dificultam a identificação dos ciclos/formações. Por meio de correlações detalhadas, entretanto, são reconhecidas seqüências deposicionais que proporcionam um mapeamento cronoestratigráfíco da parte superior da Formação Campo Mourão e da Formação Taciba (primeira parte deste trabalho). As duas seqüências do topo da Formação Taciba apresentam algumas características semelhantes às dos deltas pós-glaciais do Membro Triunfo/Formação Rio Bonito, e também serão objeto de detalhe (segunda parte do trabalho). 


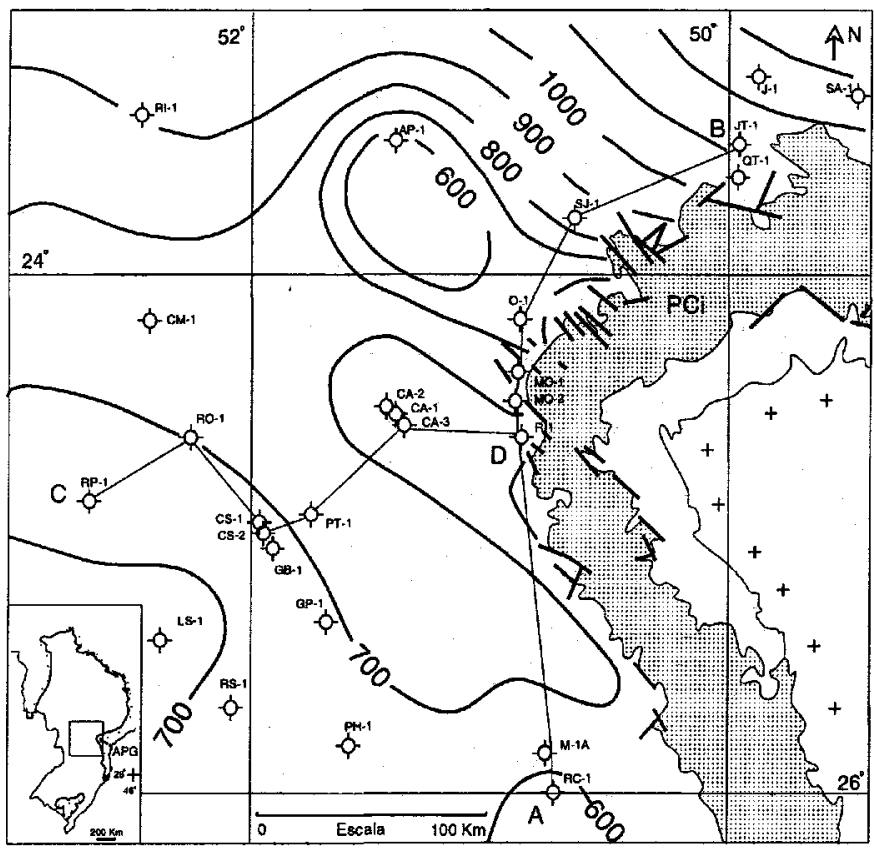

Figura l - Mapa de isópacas do Grupo Itararé mostrando a localização dos poços estudados; notar o Arco de Ponta Grossa, orientando a faixa aflorante (Pd) na direção NO-SE. No desenho interno, a localização da área trabalhada dentro da Bacia do Paraná; $A P G$, Arco de Ponta Grossa.

MÉTODOS E BASE DE DADOS Este trabalho baseia-se na correlação estratigráfica detalhada de perfis de 21 poços profundos, fornecidos pela Petrobrás ou obtidos da literatura (por exemplo França \& Potter 1988) (Fig. 1). A ênfase é na correlação dos poços perfurados junto à faixa subaflorante do leste paranaense, acrescida da análise de testemunhos. Outros dados, provenientes de numerosas sondagens rasas realizadas pela Cia. de Pesquisa de Recursos Minerais - CPRM ao longo da referida faixa subaflorante, envolvem a análise de testemunhagens contínuas e perfílagens elétricas (Aboarrage \& Daemon 1975, Aboarrage \& Lopes 1986).

A correlação entre os poços profundos é representada em duas seções estratigráfícas: uma segundo o mergulho (oeste-leste), ao longo da área central (seção CD, Fig. 4), e outra segundo a direção (sul-norte), junto a borda subaflorante leste (seção AB, Fig. 3). Um mapa (Fig. 2) ilustra as curvas de isópacas do intervalo Membro Lontras-Formação Taciba, e a razão arenito-pelito do intervalo analisado (parte superior da Formação Campo Mourão e Formação Taciba).

A correlação dos perfis das sondagens rasas da CPRM é mostrada por meio de uma seção estratigráfica (seção EF, Fig. 6), e também por uma seção detalhada com os poços testemunhados (seção EG, Fig. 7); esta suporta a correlação da parte superior da seção estratigráfica $\mathrm{AB}$ e detalha a paleogeografia proposta para a seqüência 4 da Formação Taciba (Fig. 5), completando a base de dados deste trabalho.

ANÁLISE CRONOESTRATIGRÁFICA O mapa de isópacas para o intervalo estudado, entre o Folhelho /Membro Lontras e o topo da Formação Taciba (Fig. 2), mostra quatro áreas de maior espessura, com valores acima de $300 \mathrm{~m}$ : a noroeste, área do 2-RI-1 -PR, a sudoeste, área do 2-LS-1-PR, a nordeste, área do 1-JT-1-PR; e localmente a sudeste, poço 1-RC-1-PR. A área central do mapa revela menor espessura, com valores abaixo de $200 \mathrm{~m}$ : poços 2-AP-1-PR ao norte, 1-RP-1-PR a oeste, 1-PH-1-PR a sul, e 1-R-1-PR a leste (sigla abreviada dos poços, na figura 2, é RI-1, LS-1, JT-1, RC-1, AP-1, RP-1, PH-leR-1).

A área central do mapa da figura 2 apresenta baixos valores da razão arenito:pelito (este último incluindo diamictito, siltito e folhelho), espessuras menores e predomínio de diamictitos.

O mapa de razão arenito:pelito exibe quatro áreas com valores superiores a 0,5 , coincidentes com os depocentros anteriormente referidos. Um bom exemplo é a margem NE, onde o elevado suprimento arenoso provindo da região do 1-JT-1-PR e 2-J-1-PR pode alcançar a área do poço 2-AP-1-PR. A única exceção é a área centroleste, poço 1 -R-1 -PR, caracterizada por elevado suprimento e reduzida espessura (Fig. 2).

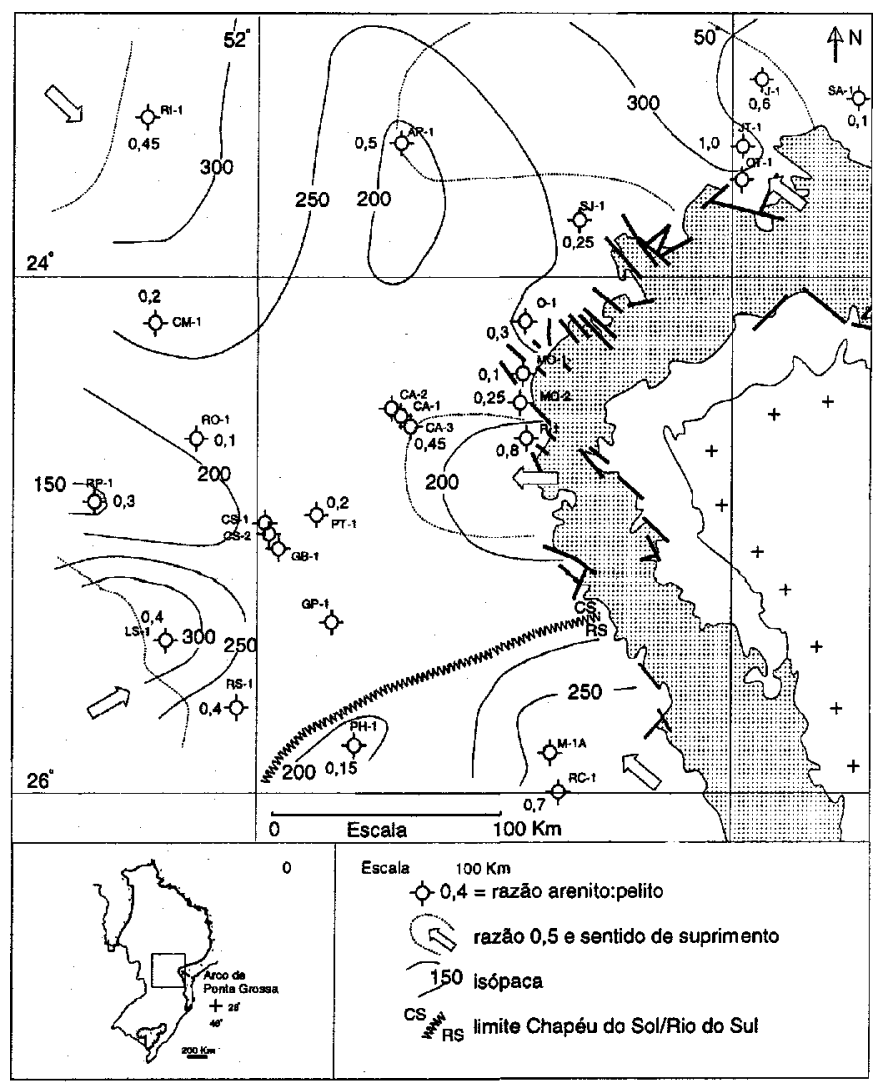

Figura 2 - Mapa de isópacas e de razão arenito-pelito do intervalo Membro Lontras-Formação Taciba. Notar as menores espessuras na porção central, onde há predomínio de diamictitos. Os maiores valores ocorrem nos quadrantes $N O, N E$, SE e SO, e coincidem com as áreas principais de suprimento de arenitos (razão acima de 0,5), indicadas pelas setas.

A distribuição centrípeta do fornecimento arenoso indica que a área oeste do mapa, mesmo que posicionada atualmente mais para leste do eixo da Bacia do Paraná, foi expressivamente suprida de uma área mais a oeste. Nos poços 2-RI-1-PR e 2-LS-1-PR (a noroeste e sudoeste, respectivamente), o suprimento está concentrado mais ao nível do Membro Rio Segredo; no poço 1-RC-1-PR, a sudeste, o alto teor arenoso corresponde ao Membro Rio Segredo e à parte superior da Formação Taciba, caracterizanda pela presença de sucessões deltaicas semelhantes às da Formação Rio Bonito sobreposta (Fig. 2).

Foram identificadas cinco seqüências deposicionais no intervalo (parte superior da Formação Campo Mourão - Formação Taciba), designadas 1 a 5 . As cinco seqüências são mapeáveis em toda a área de trabalho (exceto a seqüência 1 , por razões que serão expostas a seguir), e as seções das figuras seguintes ilustram a sua distribuição espacial. A organização vertical ascendente de cada seqüência é formada por arenito, diamictito e folhelho, e reproduz os grandes ciclos propostos por França \& Potter (1987).

Na verdade, a parte superior da Formação Campo Mourão é formada por uma espessa seção de diamictitos sobreposta pelos folhelhos do Membro Lontras (França \& Potter op.cit.). O Folhelho Lontras apresenta uma ampla distribuição e um marcante contato abrupto, caracterizando um nível transgressivo de inundação máxima (?) no topo da seqüência 1 e assim representando um evento cronoestratigráfico na bacia (Fig. 3). Na base da seqüência 2, e sobrepondo-se erosivamente ao Folhelho Lontras, desenvolvem-se os arenitos do Membro Rio Segredo, originalmente proposto por França \& Potter (1987). Os limites inferiores das seqüências 3, 4 e 5 também representam importantes superfícies erosivas de regressão (prováveis vales incisos), constituindo limites de seqüências deposicionais (sensu Van Wagoner et al. 1988).

Retornando ao mapa e à seção estratigráfica (Figs. 2 e 3), nota-se que os elevados teores arenosos das áreas centro-leste e nordeste se devem às seqüências 3 e 4 (poço 1-R-l-PR), ou às seqüências 2 e 3 (1-JT-1-PR). A seção estratigráfica segundo o mergulho (Fig. 4) demonstra a dispersão para oeste (1-CA-3-PR) do suprimento proven- 
$S$



Figura 3 - Seção estratigráfica AB, ao longo da faixa subaflorante do Grupo Itararé no leste paranaense, mostrando a distribuição das cinco seqüências deposicionais (l a 5). Notar a subdivisão da seqüência l, a cunha elástica da seqüência 3 (subdividida em 3 a e $3 b$, a norte), bem como a ocorrência da seqüencia 5 somente no sul da área. L, Folhelho Lontras; RS, Membro Rio Segredo; T, Membro Triunfo; datum no contato dos membros Triunfo e Paraguaçu, Formação Rio Bonito. Linhas espessas indicam limites de seqüência; perfil raio gama em cada poço, exceto 1-RC-1-PRe2-O1-PR(perfil SP).

W

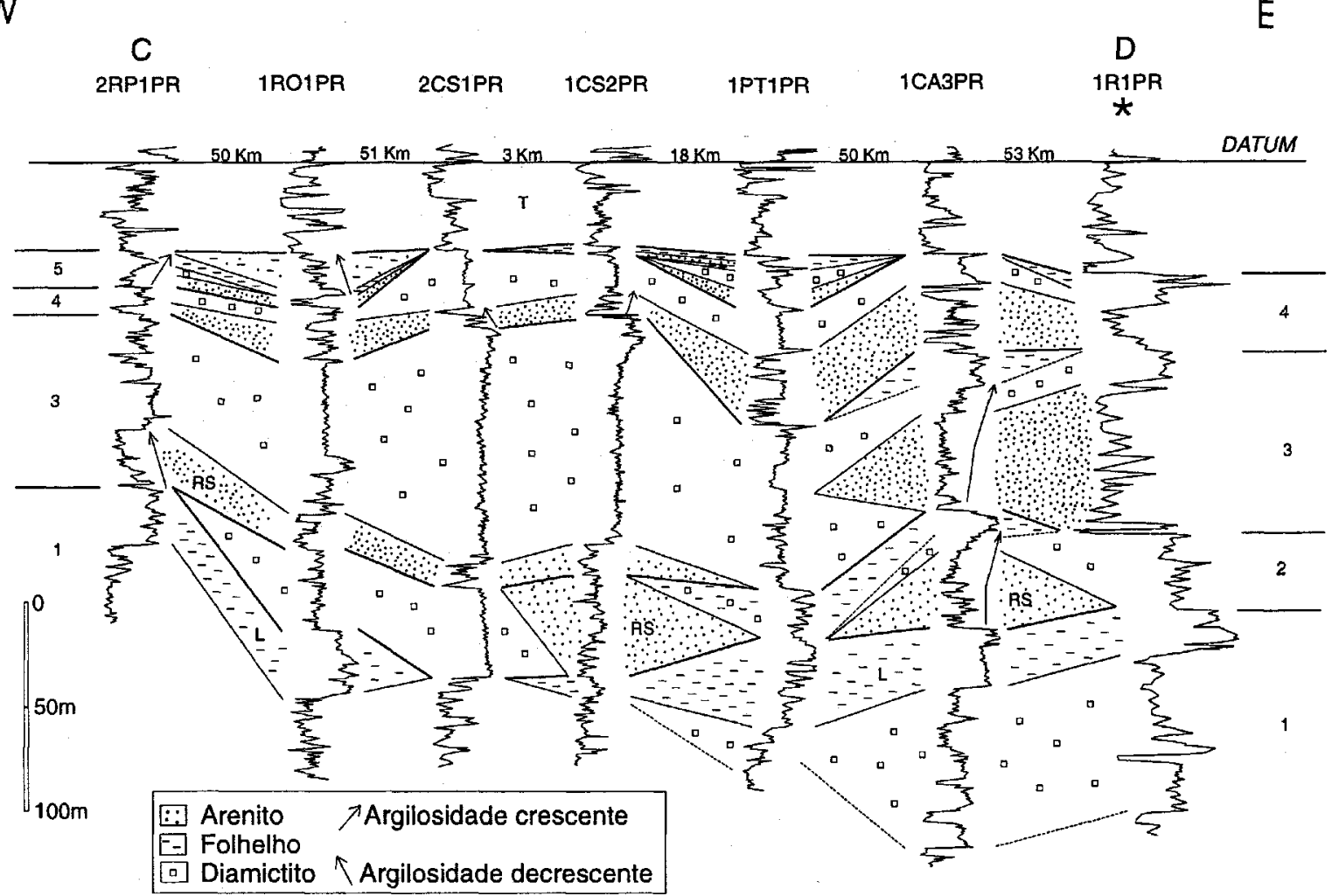

Figura 4 - Seção estratigráfica $C D$, no sentido do mergulho da bacia, mostrando a distribuição das seqüências deposicionais 1 a 5; notar o acunhamento para oeste dos diamictitos da seqüência 2, a cunha elástica da seqüência 3, e a seqüência 5 (deglaciação) do poço 1-RO-1-PR, esta ocupando paleovale escavado nos diamictitos da seqüencia 4 do poço 2-CS-1-PR. L, Folhelho Lontras; RS, Membro Rio Segredo; T, Membro Triunfo; datum no contato entre os membros Triunfo e Paraguaçu, Formação Rio Bonito. 


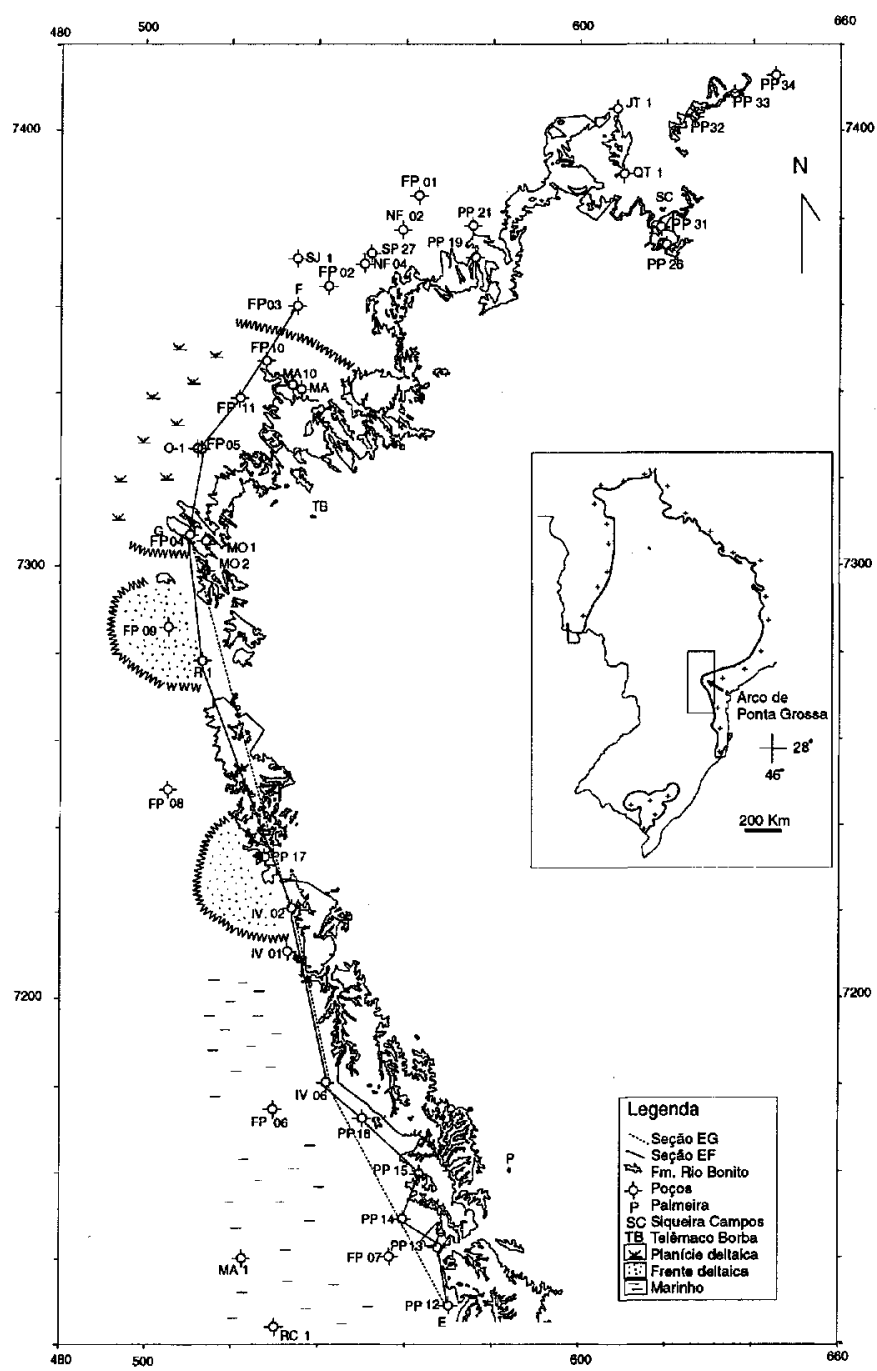

Figura 5 - Mapa de localização dos poços perfurados junto à faixa subaflorante da Formação Rio Bonito, e sistemas deposicionais da Seqüencia 4. Sistema marinho plataformal domina a porção sul, frente deltaica o centro-sul, e frente/planície deltaicas o centro-norte. Notar o acunhamento da seqüencia 4 ao norte da área. Desenho interno: localização desta figura no mapa da Bacia do Paraná.

iente da área do 1-R-1-PR. Outras dispersões são observadas, para oeste (2-AP-1-PR) e sudoeste (1-SJ-1-PR e 2-O-l-PR), dos sedimentos provindos da área do 1-JT-1-PR e 2-J-1-PR (Figs. 2 e 3).

Três sistemas deposicionais estão presentes em cada seqüência estudada: diamictitos, arenitos e folhemos (inclusive ritmitos finos). Os diamictitos apresentam-se em seções espessas ("caixa"), ou na porção intermediária das seqüências ou de pequenos ciclos com afinamento para cima (entre arenitos e folhelhos). No primeiro caso, os diamictitos estão associados a plataformas glácio-marinhas, e nos demais ao afogamento transgressivo de sucessões flúvio-deltaicas.

Os arenitos se apresentam como cunhas, originadas a partir das margens da bacia (principalmente de leste), e provavelmente representam sistemas flúvio-deltaicos e flúvio-estuarinos. Sua posição na base das seqüências indica uma origem a partir do rebaixamento do nível de base, com provável formação de vales incisos.

Os folhelhos e ritmitos finos estão associados com o máximo de cada fase transgressiva; um bom exemplo é o Folhelho Lontras, que é reconhecido até mesmo no Estado de S. Paulo. A seguir as cinco seqüências deposicionais, com os seus sistemas constituintes, são analisadas.

Seqüência 1 A seqüência 1 é representada por uma espessa seção de diamictitos e pelo Folhelho Lontras, da parte superior da Formação Campo Mourão. Está bem desenvolvida na porção leste da área, onde os diamictitos alcançam espessuras entre $60 \mathrm{~m}$ no poço 1-MO-2-PR, e 120m no poço 2-O-1 -PR; na porção central da área estudada, a unidade adelgaça de leste para oeste (Figs. 3 e 4). Outras espessuras significativas da unidade são observadas a noroeste (2-RI-1-PR e 2-CM-1-PR) e a sudoeste (1-RS-1-PR e 1-PH-1-PR) (Fig. 2).

A análise vertical da seqüência 1 permite identificar duas sucessões de argilosidade decrescente para cima, formadas individualmente por folhelho, diamictito e arenito; as sucessões indicam uma tendência a raseamento ascendente, podendo ser comparadas a parasseqüências. A seqüência 1 se completa com o evento transgressivo do Folhelho Lontras, que localmente (1-PT-1-PR) encontra-se interdigitado com diamictitos (Figs. 3 e 4 ).

Seqüência 2 A seqüência 2 é formada por quatro tipos de sucessão: a) com aumento de argilosidade para cima, desde arenitos até diamictitos e folhelhos, como no poço 1-CA-3-PR, ou com arenitos sendo sucedidos por diamictitos, poços 1-CS-2-PR e l-S J-1-PR; b) basicamente arenitos, como no poço 1-JT-1-PR, ou diamictitos, poços 1-R-1-PR e 2-MO-1-PR (Figs. 3 e 4). Os arenitos representam o Membro Rio Segredo, que no entanto está ausente em grande parte dos poços da margem leste (entre o 1-R-1-PR e o 2-O-1-PR) e nos poços 1-PT-1-PR, 2-CS-1-PR e 1-PH-1-PR (Figs. 2 a 4).

Seqüência 3 A seqüência 3 é caracterizada por uma espessa seção de diamictitos, superior a $100 \mathrm{~m}$ na área central, que se distribui amplamente na bacia e corresponde ao Membro Chapéu do Sol; subordinadamente ocorrem arenitos. Para sul e sudeste, entretanto, aquelas litologias gradam aos folhelhos, siltitos e ritmitos delgados do Membro Rio do Sul (França \& Potter 1988), como nos poços 1-PH-lPR e 1-RC-1-PR (Fig. 2).

A extensa e uniforme plataforma glácio-marinha que o pacote diamíctico representa, recebe em suas margens leste e oeste importantes contribuições de cunhas elásticas. Dois pulsos arenosos maiores são reconhecidos na fonte nordeste, próxima aos poços 1-JT-1-PR a 2-O-1 -PR, e que constituem as porções basais de divisões da seqüência 3 (3a e $3 \mathrm{~b}$ ); apenas um pulso é observado na fonte centro-leste (seqüência 3 indivisa), nos poços 1-R-1-PR e 1-CA-3-PR (Figs. 3 e 4).

$\mathrm{O}$ arranjo vertical da unidade é basicamente agradante, com diamictitos (1-PT-1-PR, 1-MO-2-PR) ou sucessões de argilosidade crescente para cima: arenito-diamictito (poços 1-R-1-PR, l-CS-2-PR)earenitodiamictito-folhelho (poço 1-CA-3-PR) (Figs. 3 e 4).

Seqüência 4 A seqüência 4 distribui-se menos amplamente que a anterior: assim, não está presente na margem nordeste, poços 1 -SJ1-PR e 1-JT-1-PR, onde a Formação Rio Bonito está assentada diretamente sobre a seqüência 3 (Figs. 2 e 3).

$\mathrm{O}$ arranjo básico da seqüência é agradante, e já apresenta sucessões deltaicas semelhantes às do Membro Triunfo da Formação Rio Bonito. $\mathrm{O}$ arenito da base da seqüência 4, bem representado nos poços 1-MO2-PR e 1-PT-1-PR, apresenta grandes variações de espessura, provavelmente devido à natureza erosiva de seu limite inferior; sobre os arenitos ocorre um corpo de diamictito glácio-marinho, já não tão espesso como os anteriores (até $30 \mathrm{~m}$ no poco 1-MO-2-PR), localmente evolui para folhelho no poço 1-R-1-PR. Na seqüência 4 é importante notar a variação faciológica para norte: nesta área, representada pelo poço 2-O-1-PR, os diamictitos estão ausentes e só ocorrem depósitos deltaicos e marinhos (ver capítulo seguinte). O suprimento provém da margem centro-leste (Figs. 2 a 4 ).

Seqüência 5 A seqüência 5 é bastante localizada, restringindo-se ao extremo sudeste da área; apresenta depósitos deltaicos, marinhos e glácio-marinhos de razoável tabularidade, e que se estendem até o norte catarinense. O suprimento provem da margem sudeste. Os arenitos deltaicos foram observados nos poços 1-RC-1 -PR, 1-PT-1 -PR e 1-RO1-PR (Figs. 2 a 4).

Detalhamento das seqüências 4 e 5: o topo transicional da Formação Taciba É possível detalhar as seqüências 4 e 5 por meio de sondagens rasas da CPRM, dispostas ao longo da faixa subaflorante da Formação Rio Bonito, e facilmente correlacionáveis aos poços profundos utilizados anteriormente na figura 3. Assim, veremos que os poços PP12, FP4, FP5 e FP3 estão próximos dos poços 1-RC-1-PR, 2-MO-1-PR, 2-O-1-PR e 1-S J-1-PR, respectivamente (Fig. 5).

Com o apoio dos dados das sondagens rasas, observa-se que a seqüência 4 distribui-se amplamente no leste paranaense, só não alcançando a porção norte (a partir dos poços FP3 e l-S J-1-PR, figuras 3 e 5). Além do mais, a disponibilidade de testemunhos possibilita uma interpretação faciológica/ambiental mais acurada, como se observa na correlação detalhada da próxima figura. Torna-se assim viável mapear 


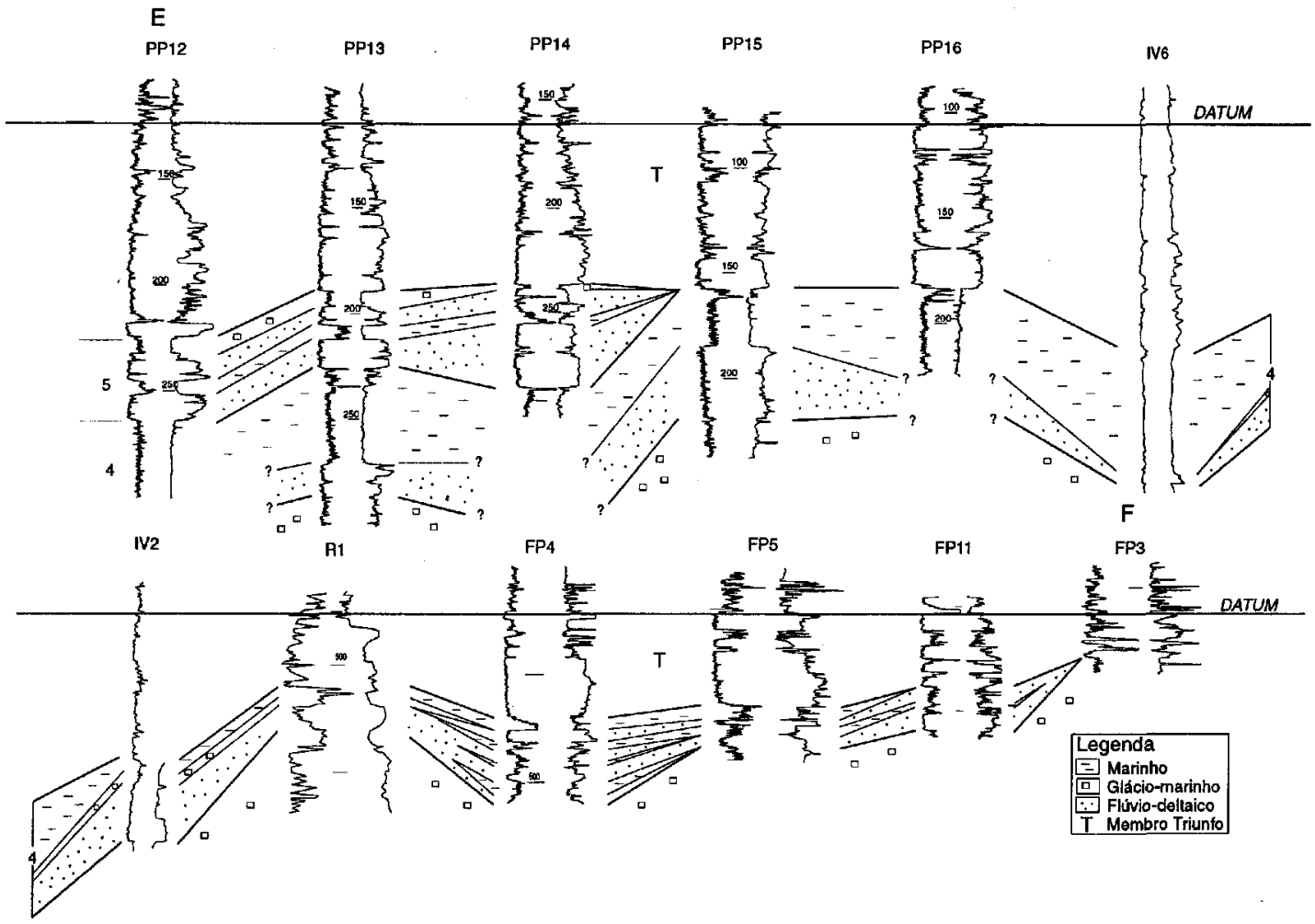

Figura 6 - Seção estratigráfica (EF) com poços rasos perfurados junto à faixa subaflorante da Formação Rio Bonito (a margem direita da figura superior emenda com a margem esquerda da figura inferior). A seqüencia 4 mostra um domínio marinho ao sul (PP12 a IV6), frente deltaica ao centro-sul (IV2 e 1-R-1-PR), e frentelplanície deltaicas ao centro-norte (FP4 a FP11); a seqüência está ausente ao norte da área (FP3). A seqüência 5 está restrita ao extremo sul da área (PP12 a PP14), onde se destacam quatro sistemas. Datum é o topo do Membro Triunfo

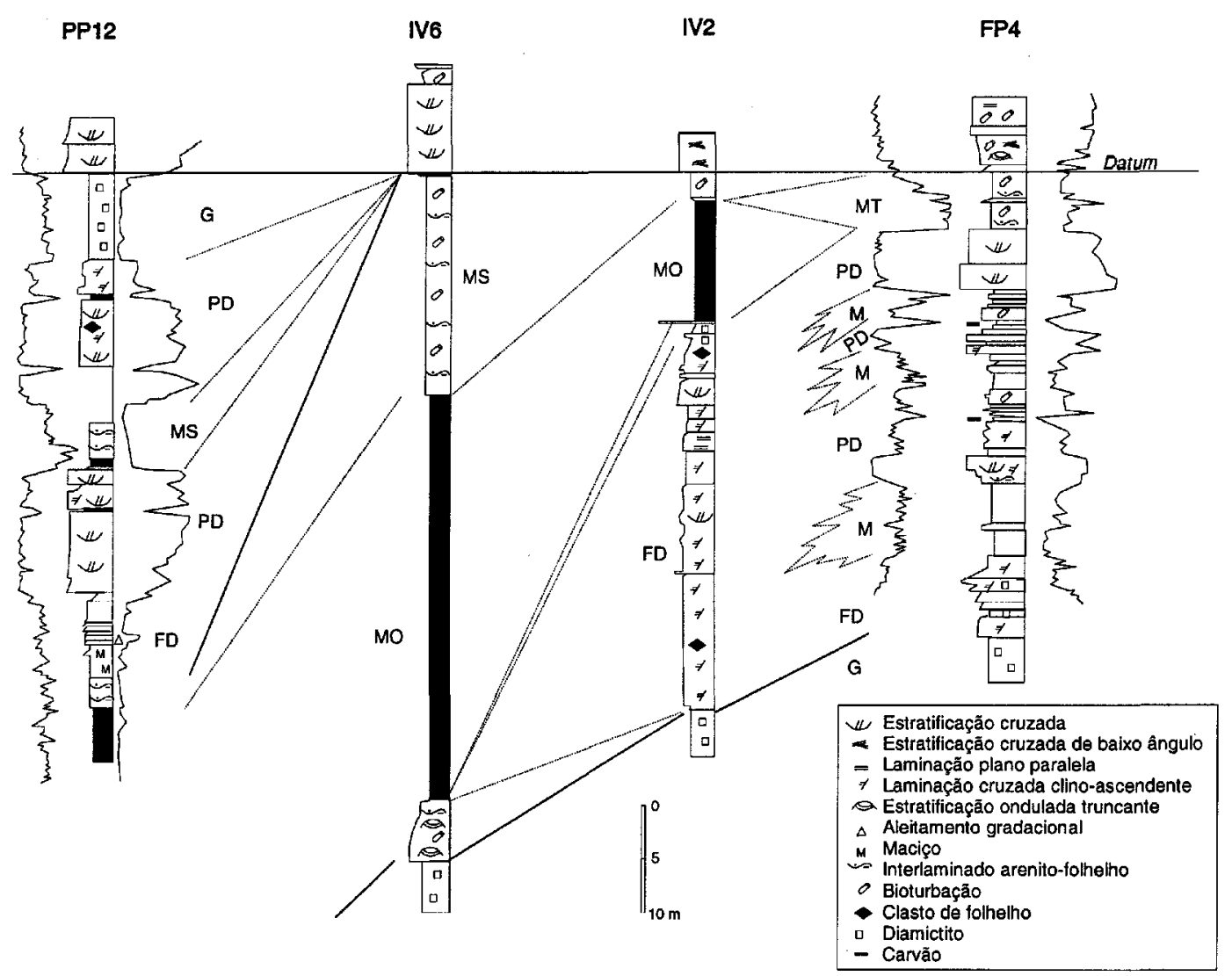

Figura 7 - Correlação estratigráfica de detalhe entre os poços testemunhados PP12 a FP4, mostrando as variações faciológicas que ocorrem na seqüencia 4 e o desenvolvimento de sistemas deltaicos, marinho e glácio-marinho na seqüencia 5, no extremo sul da área (poço PP12). PD, $F D, M O, M S, M T, G$ : sistemas de planície deltaica, frente deltaica, marinho offshore, marinho shoreface, marinho de tempestades e glácio-marinho, respectivamente. Datum no topo do Grupo Itararé. 
os paleoambientes da seqüência 4 ao longo da faixa subaflorante do leste paranaense.

Já a seqüência 5 é restrita aos poços mais ao sul, do PP12 ao PP14, e o 1-RC-1-PR (Figs. 3 e 5).

A SEQÜENNCIA 4 A seqüência 4 está assentada em diamictitos do topo da seqüência 3 . Como se observa na figura 6 , três áreas se destacam: sul, poços PP12 a IV6, centro-sul, poços IV2 e 1-R-1-PR, e centro, poços FP4 a FP11.

A área sul apresenta uma sucessão ascendente de aumento de argilosidade e depois diminuição: arenitos são sucedidos por folhelhos, e estes por arenitos/folhelhos interlaminados por ondas e bioturbados. Dados de testemunho atestam a natureza marinha das duas últimas associações faciológicas. Os arenitos basais apresentam estratifícações onduladas truncantes e progressiva bioturbação para o topo, de ambiente marinho; no poço IV6; em outras áreas, por exemplo na do poço PP13, as características do perfil sugerem uma origem flúvio-deltaica (Figs. 6 e 7).

A área centro-sul apresenta uma espessa seção de arenitos sucedida por diamictitos, folhelhos e interlaminações arenito-folhelho, ou seja, uma sucessão ascendente de aumento seguida por uma diminuição de argilosidade (Fig. 6). Os testemunhos do poço IV2 revelam arenitos muito finos com laminação cruzada clino-ascendente sucedidos por arenitos finos/médios com laminação plano-paralela e estratificação cruzada, de frente deltaica distal a proximal; seguem diamictitos, já indicando um afogamento do sistema deltaico, que culmina com a deposição marinha dos folhelhos e interlaminações por ondas de arenito e folhelho (Fig. 7)

A área central apresenta intercalações de arenitos, siltitos, folhelhos e localmente carvões, com um padrão agradante geral resultante da recorrência de fácies marinhas e deltaicas; a sucessão ascendente de aumento de argilosidade, exibida pelo poço FP11, é reflexo de um evento transgressivo que ocorre no topo da seqüência 4 nos poços FP4 e FP5 (Figs. 5,6 e 7). As estruturas e texturas presentes nos testemunhos indicam ambientes marinhos e deltaicos, estes incluindo frente e planície deltaicas; o evento transgressivo do topo (FP4, Fig. 7) é representado por interlaminações arenito-folhelho com aleitamento gradacional, originadas por ondas de tempestade e comumente retrabalhadas por bioturbação.

O mapa paleogeográfico da figura 5 apresenta os principais ambientes reinantes quando da deposição da seqüência 4, e mostra condições transicionais passando a marinhas no sentido norte-sul.

A SEQÜENNCIA 5 A seqüência 5 está restrita ao extremo sul paranaense e norte catarinense, e apresenta um nítido padrão de bolo-decamadas formado pela alternância de fácies arenosas, areno-argilosas e diamíctas. Como exemplificado pelo poço PP12, as fácies arenosas estão relacionadas a duas sucessões deltaicas que são afogadas, transgressivamente por fácies argilosas marinhas e diamíctas glácio-marinhas (Figs. 6 e 7).

As associações deltaicas exibem um padrão de granocrescência ascendente: siltitos maciços e delgados ritmitos arenito-folhelho com aleitamento gradacional, de frente deltaica, são sucedidos por arenitos grossos a finos, com estratificacão e laminação cruzadas, de planície deltaica. A associação marinha é formada por interlaminações arenitofolhelho por ondas, enquanto a associação glácio-marinha do topo da seqüência é composta por um diamictito maciço com espessura de $8 \mathrm{~m}$ (Fig. 7).

DISCUSSÃO E CONCLUSÕES O Folhelho Lontras constitui um marco transgressivo regional e importante elemento da correlação cronoestratigráfica proposta neste trabalho. Espessos diamictitos e o Folhelho Lontras constituem os elementos transgressivos da seqüência
1, tendo sido mapeados na margem leste e quadrantes $\mathrm{NO}$ e $\mathrm{NE}$ da área, e estando ausentes na porção centro-oeste.

Exceto a porção sudeste do Paraná, onde predominam os elásticos síltico-argilosos do Membro Rio do Sul (poços 1-PH-1-PR e 1-RC-1PR), toda a deposição das formacões Campo Mourão (parte superior) e Taciba é dominada por diamictitos de um ambiente glácio-marinho plataformal. França \& Potter (1988) referem-se aos diamictitos como "geleiras marinhas", identificando um grande lobo de entrada de lamito seixoso, localizado sobre o Arco de Ponta Grossa.

A seqüência 2 já apresenta típico padrão agradacional, com base erosiva e granodecrescência ascendente. Os arenitos da seqüência 2 representam cunhas elásticas alimentadas das margens da bacia, como os arenitos das demais seqüências, e constituem o Membro Rio Segredo de França \& Potter (1988). Estes autores não mapearam cunhas elásticas no Paraná, e sim em S. Paulo e sul de Santa Catarina; em S. Paulo, um extenso lobo arenoso origina-se no sul do Estado e se dirige para norte, em direção a Bauru.

As seqüências 3 e 4 são caracterizadas pela entrada de cunhas de elásticos grossos a partir das margens da bacia; as principais áreas-fontes dos arenitos são as margens nordeste e centro-leste, e secundariamente a margem oeste. Dados de testemunhos indicam um rápido acunhamento desses arenitos para oeste; mudanças faciológicas, no mesmo sentido de leste para oeste, são verificadas, passando de fluvial até estuarino/deltaico.

A porção superior preservada do Grupo Itararé, sotoposta à discordância do topo, é progressivamente mais nova para o sul: assim subafloram, nesse sentido, as seqüências 3,4 e 5 . Isso se deve ao deslocamento progressivo da sedimentação em direção ao centro da bacia (ao sul), ou à erosão dos sedimentos, mais acentuada na borda norte em soerguimento. Em apoio a esta última hipótese, deve-se lembrar que o Membro Triunfo (base da Formação Rio Bonito) acunha-se no mesmo sentido até desaparecer no norte paranaense: nesta área, o Membro Paraguaçu (parte média da Formação Rio Bonito) assenta-se discordantemente sobre o Grupo Itararé.

As seqüências superiores 4 e 5 apresentam elementos deltaicos semelhantes aos do Membro Triunfo, e seus diamictitos tornam-se progressivamente menos espessos e mais restritos em área; os folhelhos marinhos dessas seqüências são conhecidos como Camadas Passinho. Dentro da seqüência 4 é marcante a mudança faciológica dentro da cunha arenosa, no sentido sul-norte, de sistemas marinho para frente deltaica e desta para planície deltaica (portadora de carvão), estes dois últimos semelhantes aos que se desenvolvem no Membro Triunfo na mesma área.

Aboarrage \& Daemon (1975) e Popp (1983) analisaram a Formação Rio Bonito e a passagem Itararé-Triunfo nas margem leste da bacia e no sul paranaense, respectivamente. Ambos mapearam uma unidade marinha ou prodeltaica no topo do Grupo Itararé, e que corresponde às seqüências 4 e 5 do presente trabalho; ambos os trabalhos, entretanto, não individualizaram as referidas seqüências.

As seqüências deposicionais ora caracterizadas constituem a melhor ferramenta de divisão e mapeamento cronoestratigráfico para este intervalo do complexo Grupo Itararé. Pelo menos cinco fases de ativa sedimentação glácio-marinha foram reconhecidas, sendo sucedidas por cunhas elásticas de influxo de sedimentos mais grossos na base de cada seqüência. A provável origem para essas cunhas elásticas e canalizadas pode ser o rebaixamento do nível de base, ocasionando vales incisos que foram posteriormente preenchidos por depósitos flúvio-deltaicos.

Agradecimentos À PETROBRÁS e à CPRM, pelo acesso aos dados de subsuperfície. A Profa. Rosemarie Rohn, pela leitura do trabalho, e à Marília, pela confecção de todas as ilustrações.

\section{Referências}

Aboarrage M. \& Daemon R.F. 1975. Relatório integrado dos projetos: Carvão no extremo none de Santa Catarina, Prospecção de Carvão no Paraná II, Carvão no Estado de S. Paulo. DNPM/CPRM, relatório interno.

Aboarrage M. \& Lopes R.C. 1986. Projeto A Borda Leste da Bacia do Paraná: integração geológica e avaliação econômica. DNPM/CPRM, relatório interno, 18 vis.

França A.B. \& Potter P.E. 1988. Estratigrafia, ambiente deposicional e análise de reservatório do Grupo Itararé (Permocarbonífero), Bacia do Paraná (Parte 1). Boletim de Geociências da Petrobrás, 2:147-191.

Milani E.J., França A.B., Schneider R.L. 1994.6-Bacia do Paraná. Boletim de Geociências da Petrobrás, 8:69-82.

Popp,J.H. 1983. Fácies, ambientes e carvões na Formação Rio Bonito, no sul do Estado do Paraná: uma análise estratigráfica. Revista Brasileira de Geociências, 13:27-36.
Schneider R.L., Mühlmann H., Tommasi E., Medeiros R. A., Daemon R.F., Nogueira A. A. 1974. Revisão estratigráfica da Bacia do Paraná. In: SBG, Congresso Brasileiro de Geologia, 28, Porto Alegre, Anais, 1:41-65.

Van Wagoner J.C., Posamentier H.W., Mitchum R.M., Vail P.R.,Sarg J.F., Loutit T.S., Hardenbol J. 1988. An overview of the fundamentals of sequence stratigraphy and key definitions. In C.K.Wilgus et al. (eds.) Sea-level changes: an integrated approach. Tulsa, S.E.P.M., 39-45.

Manuscrito A-1035 Recebido em 15 de outubro de 1998 Revisão dos autores em 01 de fevereiro de!999 Revisão aceita em 10 de fevereiro de!999 